\title{
Anterior Cranial Fossa
}

National Cancer Institute

\section{Source}

National Cancer Institute. Anterior Cranial Fossa. NCI Thesaurus. Code C32090.

The internal area of the skull that holds the frontal lobes. 